\title{
Echocardiographic changes during acute pulmonary edema subsequent to scorpion sting
}

Delma K (1)

(1) Service of Anesthesia and Reanimation, Ouargla Hospital, Ouargla, Algeria.

\begin{abstract}
Acute pulmonary edema (APE) occurring after scorpion sting is the leading cause of death of the victims of scorpion envenomation. The APE origin is still questioned by physicians treating these patients. Based on echocardiographic study of 20 patients with severe envenomation treated in Ouargla Hospital resuscitation ward during the last four years, the APE etiology seems more likely cardiogenic, referring to cardiac symptoms confirmed by echocardiography although other mechanisms may also be involved. This hypothesis is further confirmed by the positive response of patients to the administration of dobutamine.
\end{abstract}

Key words: scorpion envenomation, acute pulmonary edema, echocardiography, dobutamine.

\section{INTRODUCTION}

In Algeria, scorpion envenomation is a major public health problem, especially in the south of the country, such as in Ouargla, where almost 2,000 scorpion stings that cause ten deaths are recorded each year $(1,2)$. Among the species found in the region, the most common and probably the most dangerous is Androctonus australis hector.

In recent years, morbidity and mortality have diminished thanks largely to better medical coverage in these regions of the Sahara, control of scorpion population and improving care (Figure 1). The latter is due to the increase and strengthening of intensive care and a better understanding, by medical personnel, of the pathophysiology of scorpion envenomation and its complications (3).

Fatalities, although rare in this context, are linked to cardiovascular complications, including envenomations by scorpions of the Ancient world (4-6). An acute pulmonary edema (APE) is involved in the majority of cases. However, controversy remains about the origin of this APE. Therefore, the present study focuses on this complication in order to provide details based on echocardiography.

We report herein the main echocardiographic changes observed in intensive care unit (ICU) patients admitted following a scorpion sting complicated by APE.

\section{PATIENTS AND METHODS}

This retrospective study involved 20 patients admitted to the ICU of Ouargla Hospital between 2008 and 2010. We used the case report form of each patient.

The province of Ouargla, an oil-rich region, is located in the southeast of the country, between $31^{\circ} 51^{\prime} \mathrm{N}-5^{\circ} 17^{\prime} \mathrm{E}$ and $31^{\circ} 68^{\prime} \mathrm{N}-5^{\circ} 17^{\prime} \mathrm{E}$ (Figure 


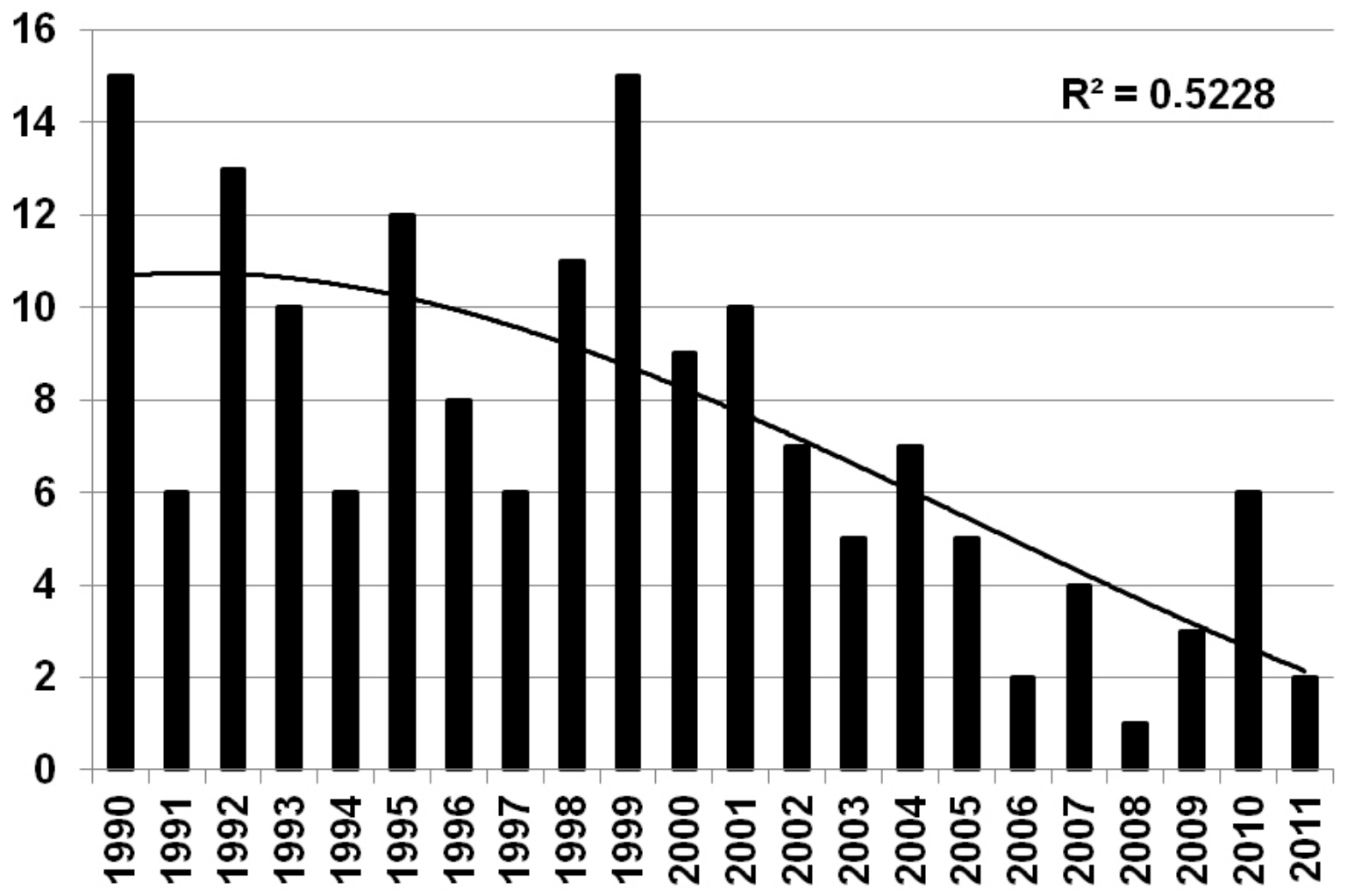

Figure 1. Trend in mortality from scorpion stings in the province of Ouargla.

2). Its population of 248,570 inhabitants (2010 census) resides in an area of $18,289 \mathrm{~km}^{2}$. The climate is very hot (up to $50^{\circ} \mathrm{C}$ ) and dry in summer.

All patients included in this study were stung by a scorpion and admitted to the ICU with APE. Excluded from the study were patients: older than 50 years and/or with known history of organ failure, cardiorespiratory insufficiency, diabetes, hypertension, pulmonary or other chronic disease.

Echocardiograms were performed by the device VIVID 3 Expert (General Electric Healthcare, NY, USA), with color Doppler, often 48 hours after the sting because hemodynamic and respiratory distress of the patient prevented us from carrying out such analyses prior to the restoration of vital functions. The tests were interpreted by a cardiologist. The examinations were performed on the patients treated with dobutamine, because this cardiotonic was administered systematically as soon as the diagnosis of pulmonary edema was suspected.

Five echocardiographic parameters were analyzed:

- the systolic ejection fraction;

- modification of the regional cardiokinetics (hypokenesia + or - extented);

- changes the systolic and diastolic diameters that vary according to age;

- graded mitral regurgitation;

- separation of the pericardium with or without effusion.

\section{RESULTS}

The age of patients ranged between 3 and 50 years, with a median (IQ: 25;75) 17.5 (12;27.3) years. A majority of patients (55\%) were adults.

All patients had a systolic ejection fraction below the standard: $42.6 \pm 3.1 \%$ versus $60 \pm 6 \%$ (Figure 3). There was no significant difference (P $=0.05)$ between children $(43.9 \pm 3.7 \%)$ and adults $(41.5 \pm 4.9 \%)$. 


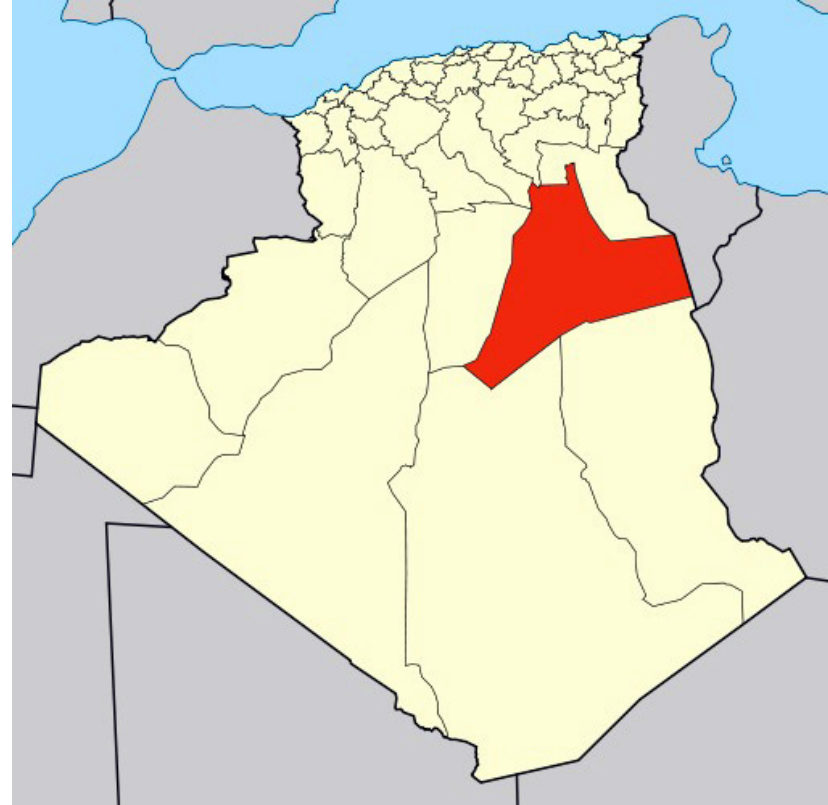

Figure 2. Location of the province of Ouargla in Algeria.
All patients presented disorders of myocardiac kinetics, presenting a shape resembling a myocardial akinesia or hypokinesia, mostly septal or anterior (Table 1), which, in five cases, affected the entire myocardium.

Measurements of telediastolic and telesystolic diameters (TDD and TSD, respectively) were within the normal range (Table 1). However, fractional shortening of the left ventricle given by the formula = FSLV (TDD-TSD)/TDD $\times 100$ was abnormal in 13 of the 19 patients measured. FSLV average was $20.1 \pm 2.1 \%$, significantly below the normal range $30 \pm 5 \%(P=0.05)$. There was no significant difference $(\mathrm{p}=0.05)$ between children $(19 \pm 2.7 \%)$ and adults $(21 \pm$ $3.2 \%)$.

In half of the cases, mitral regurgitation was found. Finally, a single case of pericardial separation was observed.

\section{Systolic ejection fraction}

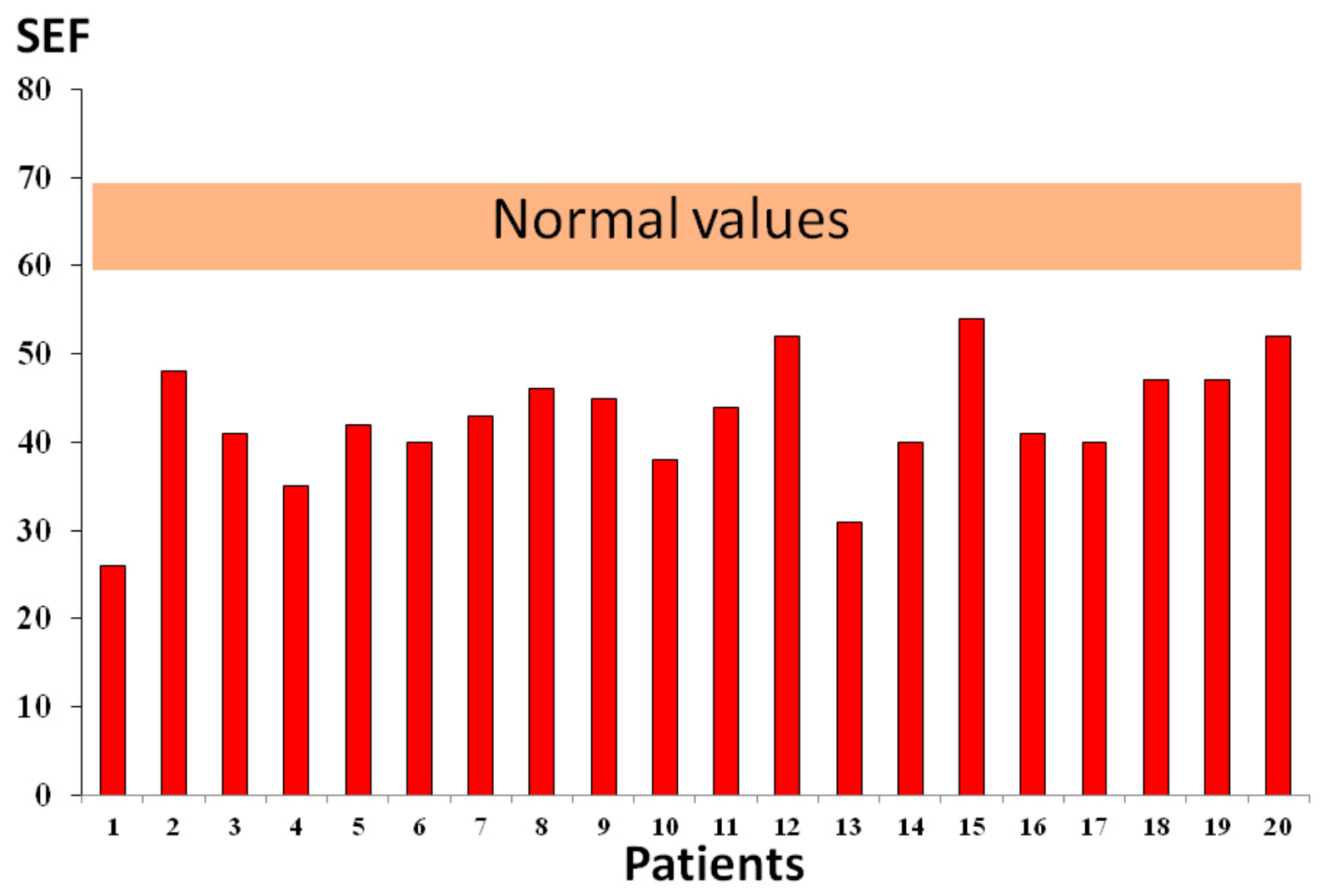

Figure 3. Measurements of systolic ejection fraction in ICU patients of the Ouargla Hospital (those treated with dobutamine) 
Table 1. Changes in cardiac functions

\begin{tabular}{|c|c|c|c|}
\hline Patient & Age (years) & Myocardium kinetics & TDD - TSD $(\mathrm{mm})^{*}$ \\
\hline 1 & 50 & Anterior hypokinesia & $50-44$ \\
\hline 2 & 35 & Septal hypokinesia & $57-42$ \\
\hline 3 & 15 & Antero-septal hypokinesia & \\
\hline 4 & 26 & $\begin{array}{l}\text { Severe hypokinesia of both interatrial septum } \\
\text { and posterior wall of left ventricle }\end{array}$ & $48-40$ \\
\hline 5 & 3 & Global hypokinesia & $36-30$ \\
\hline 6 & 35 & Antero-septal akinesia & $55-41$ \\
\hline 7 & 10 & $\begin{array}{l}\text { Severe antero-septal hypokinesia and mild } \\
\text { hypokinesia of inferior wall of left ventricle }\end{array}$ & $40-33$ \\
\hline 8 & 25 & Septal hypokinesia/hypokinesis & $53-40$ \\
\hline 9 & 18 & Hypokinesia of posterior wall of left ventricle & $49-40$ \\
\hline 10 & 31 & Global hypokinesia & $58-47$ \\
\hline 11 & 17 & Severe septal hypokinesia & $57-43$ \\
\hline 12 & 14 & Septal hypokinesia & $42-31$ \\
\hline 13 & 24 & Severe anterior hypokinesia & $51-44$ \\
\hline 14 & 12 & Global hypokinesia with septal predominance & $51-43$ \\
\hline 15 & 12 & Septal akinesia & $42-32$ \\
\hline 16 & 10 & $\begin{array}{l}\text { Global hypokinesia with antero-septal } \\
\text { predominance }\end{array}$ & $41-34$ \\
\hline 17 & 10 & Global hypokinesia & $50-42$ \\
\hline 18 & 15 & Severe septal hypokinesia & $52.5-43$ \\
\hline 19 & 21 & Severe septal hypokinesia & $50-40$ \\
\hline 20 & 31 & Mild global hypokinesia & $52-37$ \\
\hline
\end{tabular}

* TDD: telediastolic diameter; TSD: telesystolic diameter (in millimeters)

\section{DISCUSSION}

This study reported several years of experiences in an ICU of a Saharan Algerian city, among the municipalities most affected by scorpion envenomation.

The decline in mortality that we observed between 1990 and 2011 (Figure 1) is likely attributable to better care for patients upon their arrival at the hospital. However, there are severe cases, in adults as well as in children, who die of acute pulmonary edema.

APE is often diagnosed by the doctor on the basis of clinical data such as the onset of dyspnea, and/or the presence of crackles upon pulmonary auscultation, sometimes associated with hemoptysis. This clinical picture is frequently associated with symptoms of low cardiac output and tissue hypoperfusion (7). Given these symptoms, Algerian treatment protocol recommends hospitalization and prescription of emergency cardiac treatment (dobutamine) because of high risk of death.

Very often, the hemodynamic state is disturbed, most often, in our experience, in the form of hypotension. This is why the Algerian national consensus recommends avoiding the use of antihypertensive drugs, although hypertension is found at the beginning of envenomation. This hypertension can be a 
consequence of pain, anxiety or stress, but also due to the adrenergic storm caused by the inoculation of scorpion venom (8). Nevertheless, at least in the consultation delays generally observed in Algeria, envenomation quickly develops towards a major cardiac complication which involves APE.

The decrease of systolic ejection fraction results in the fall in cardiac output, itself responsible for the increased filling pressures and the occurrence of APE. The low blood pressure, whether its mechanism is a collapse of vascular resistances, a vasodilatation or a drop in cardiac output (negative inotropic effect), constitutes a therapeutic emergency.

The disorders of myocardial kinetics can reach the level of a true paralysis attack, more or less extensive, affecting primarily the anteroseptal region.

The mitral regurgitation grade 1 , found in half of the cases, does not induce sequelae and is reversible within a few weeks, probably related to changes in telediastolic - but more particularly telesystolic - diameters resulting from dilation of the left ventricle.

All of these myocardial disturbances are consistent with cell disruptions linked to the pathophysiology of scorpion toxins which block the sodium voltage-dependent channels. Our observations also argue in favor of the cardiogenic origin of acute pulmonary edema and justify prescription of such inotropic drugs as dobutamine.

These cardiac disorders are reversible. Emergency resuscitation can correct the hypotension and homeostasis disorders by means of adequate oxygen saturation.

However, we cannot exclude the participation of other mechanisms, humoral or inflammatory, in the genesis of the $\operatorname{APE}(5,6,8-10)$. In addition, the variability of venoms from scorpions particularly between Old- and New-World species - should encourage vigilance because similar clinical symptoms may involve different toxicological mechanisms. Thus, even if adjuvant therapies, in our case dobutamine, are likely to provide a satisfactory emergency solution, early administration of scorpion antivenom remains necessary (8).

\section{CONCLUSION}

The study of echocardiographic changes during APE shown after scorpion envenomation has shed light on this major physiopathological complication which is considered the main cause of death of scorpion sting victims. This study showed that APE is likely to have a cardiogenic etiology, at least in relation to the Algerian scorpions and probably also all Maghrebian ones. This should prompt the administration of dobutamine, in combination with other conventional APE treatments, namely oxygenation and ventilation delivered when the patient is in a half-sitting position, as well as avoidance of the use of drugs that are depressant to the myocardium or drugs hypotensive to the hemodynamic status. Finally, echocardiography is an important tool for the diagnosis and monitoring of cardiac involvement.

However, further pharmacological studies of scorpion venom are still necessary to improve the symptomatic treatment of scorpion envenomation.

\section{COPYRIGHT}

(C) CEVAP 2012

\section{SUBMISSION STATUS}

Received: September 28, 2012.

Accepted: November 8, 2012.

Abstract published online: November 8, 2012.

Full paper published online: November 30, 2012.

\section{CONFLICTS OF INTEREST}

The authors declare no conflicts of interest.

\section{FINANCIAL SOURCE}

The Ouargla Hospital, Algeria, supported the present study.

\section{CORRESPONDENCE TO}

Delma Kilani, Service d'Anesthésie Réanimation, Hôpital d'Ouargla, Algéria, BP 89 Gharbouz Ouargla 30032 Algeria. Phone: 213771313942. Fax 213 29762071. Email: kilani.delma@gmail. com. 


\section{REFERENCES}

1. Benguedda AC, Djébari FL, Ouahdi M, Hellal $\mathrm{H}$, Griene L, Guerenik M, et al. Expérience de quinze années de lutte contre l'envenimation scorpionique en Algérie. Bull Soc Pathol Exot. 2002;95(3):205-8.

2. Hellal H, Guerinik M, Griene L, Laid Y, Mesbah $\mathrm{S}$, Merad R, et al. Données épidémiologiques sur l'envenimation scorpionique en Algérie. Bull Soc Pathol Exot. 2012;105(3):189-93.

3. Chippaux JP, Goyffon M. Epidemiology of scorpionism: a global appraisal. Acta Trop. 2008;107(2):71-9.

4. Abroug F, Boujdaria R, Belghith M, Nouira S, Bouchoucha S. Cardiac dysfunction and pulmonary edema following scorpion envenomation. Chest. 1991;100(4):1057-9.

5. Freire-Maia L, Campos JA, Amaral CF. Approaches to the treatment of scorpion envenoming. Toxicon. 1994;32(9):1009-14.
6. Ismail $M$. The scorpion envenoming syndrome. Toxicon. 1995;33(7):825-58.

7. Rahav G, Weiss AT. Scorpion sting-induced pulmonary edema. Scintigraphic evidence of cardiac dysfunction. Chest. 1990;97(6):1478-80.

8. Chippaux JP. Emerging options for the management of scorpion stings. Drug Des Devel Ther. 2012;6:16573.

9. Adi-Bessalem S, Hammoudi-Triki D, LarabaDjebari F. Pathophysiological effects of Androctonus australis hector scorpion venom: tissue damages and inflammatory response. Exp Toxicol Pathol. 2008;60(4-5):373-80.

10. Petricevich VL. Scorpion venom and the inflammatory response. Mediat Inflamm. 2010:2010:1. Doi:10.1155/2010/903295. 